\title{
Distribuição Espacial e Temporal de Descargas Atmosféricas no Entorno de Belém
}

\author{
Maria Janete de M. Albuquerque Arthur C. Almeida \\ Mauro Alex F. Bentes* Vânia F. Coelho** \\ Faculdade de Matemática, CUNCAST, UFPA \\ 68746-360, Castanhal, PA \\ E-mail: janetecap@ hotmail.com, arthur@ufpa.br, mauro.bentes@ castanhal.ufpa.br, \\ vania.coelho@itec.ufpa.br
}

\begin{abstract}
RESUMO
Este trabalho está relacionado ao projeto de pesquisa Nuvens e Raios na Amazônia, produto de uma parceria entre a Universidade Federal do Pará (UFPA) e o SIPAM (Sistema de Proteção da Amazônia). O desempenho dos sistemas de distribuição de energia elétrica é bastante suscetível a variações no clima, muito vulnerável aos eventos extremos de chuva [1], e raios.

Aqui será feita uma distribuição espacial e temporal de descargas atmosféricas em uma área de estudo circular com raio de $100 \mathrm{Km}$ e centro no Aeroporto Internacional de Belém, utilizando-se dos dados georreferenciados de 2009 e 2010 detectados pela Sferics Timing And Ranging NETwork (STARNET), registrados de acordo com Greenwich Mean Time(GMT) e convertidos ao horário de Brasília.

Da trigonometria esférica, sabe-se que para calcular a distância entre dois pontos sobre a superfície terrestre, usa-se a fórmula abaixo utilizando as coordenadas geográficas. Desta forma, descobre se o raio caiu dentro da área analisada. E se sim, o evento é registrado.

$$
\mathrm{DD}=\mathrm{R} \cdot \operatorname{Arc} \operatorname{Cos}\left[\operatorname{Cos}\left(\mathrm{LA}_{1}-\mathrm{LA}_{2}\right) \cdot \operatorname{Cos}\left(\mathrm{LO}_{1}-\mathrm{LO}_{2}\right)\right]
$$

DD é a distância entre o ponto que caiu o raio e o centro da circunferência. $\mathrm{R}$ é o raio da Terra, aproximadamente $6378 \mathrm{Km}$.

$\mathrm{LA}_{1}$ e $\mathrm{LO}_{1}$ : latitude e longitude do centro da circunferência, respectivamente.

$\mathrm{LA}_{2}$ e $\mathrm{LO}_{2}$ : latitude e longitude do local da queda do raio

$\mathrm{LA}_{1}, \mathrm{LA}_{2}, \mathrm{LO}_{1}$, e $\mathrm{LO}_{2}$ estão em radianos. Observe que não importa o ponto (centro da circunferência ou local da queda do raio) que tem índice 1 ou 2 , já que o cosseno é função par.

Para a distribuição temporal, os dados dos anos de estudo foram separados por hora e por meses e os gráficos foram gerados no programa Octave, detectando-se que o pico de descargas atmosféricas ocorre entre $14 \mathrm{~h}$ e $18 \mathrm{~h}$ e os meses de abril a julho apresentaram maior incidência.
\end{abstract}

(a)

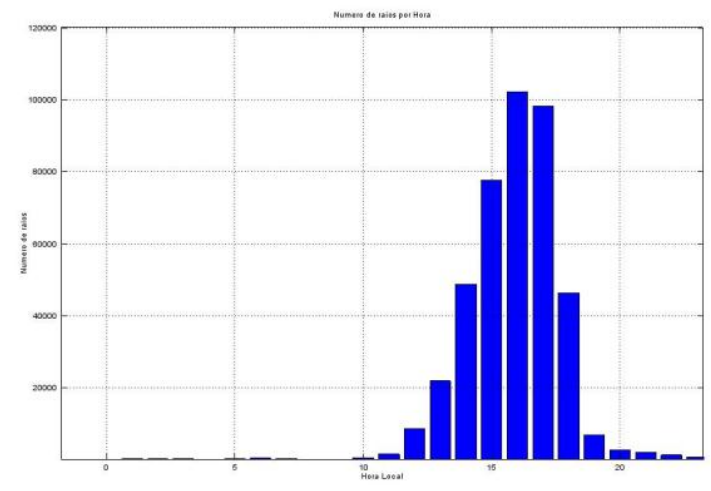

(b)

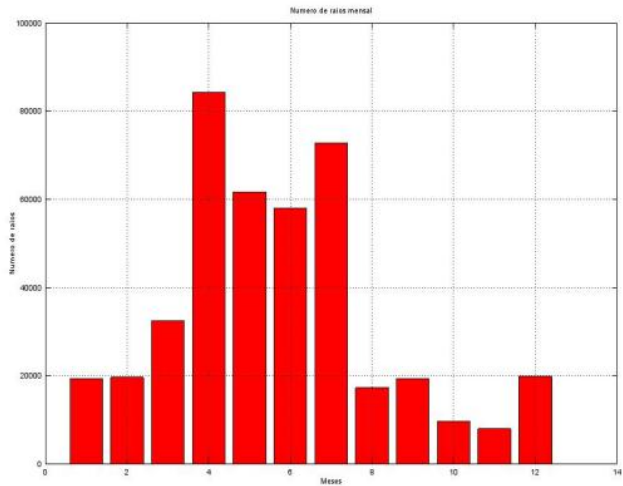

Figura 1: Distribuição horária dos raios (a) e distribuição mensal dos raios (b)

Para o estudo da distribuição espacial, foi feita a seguinte análise: como o diâmetro do círculo em estudo é igual a $200 \mathrm{Km}$, criou-se uma malha de 200 linhas por 200 colunas no programa ArcView no intuito de que cada célula compreendesse uma área de $1 \mathrm{Km}^{2}$, e para isso, estabeleceu-se a saída de tamanho de célula da malha igual a 0,009 grau decimal, o que foi

* Bolsista de Iniciação Científica PIBIC/CNPq-AF

** Bolsista de Iniciação Científica PIBIC/UFPA-Interior 
possível através de uma regra de três simples, tal que $1^{\circ}$ (um grau) corresponde a, aproximadamente, $110 \mathrm{Km}$ na linha do Equador.

Os gráficos abaixo, gerados no ArcView, mostram diversas áreas afetadas com maior incidência, em especial, no município de Barcarena e arredores.

(a)

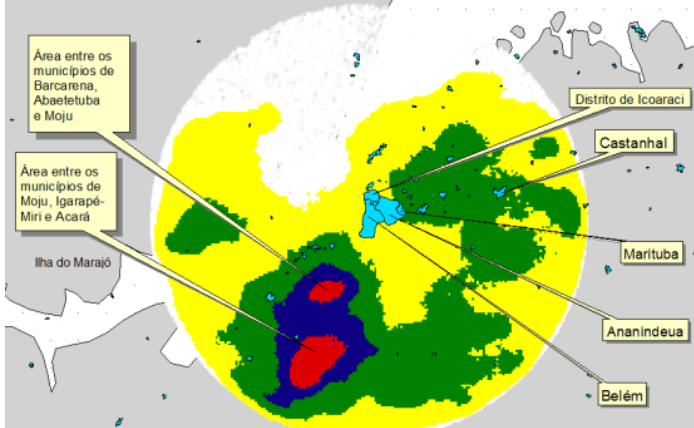

(c)

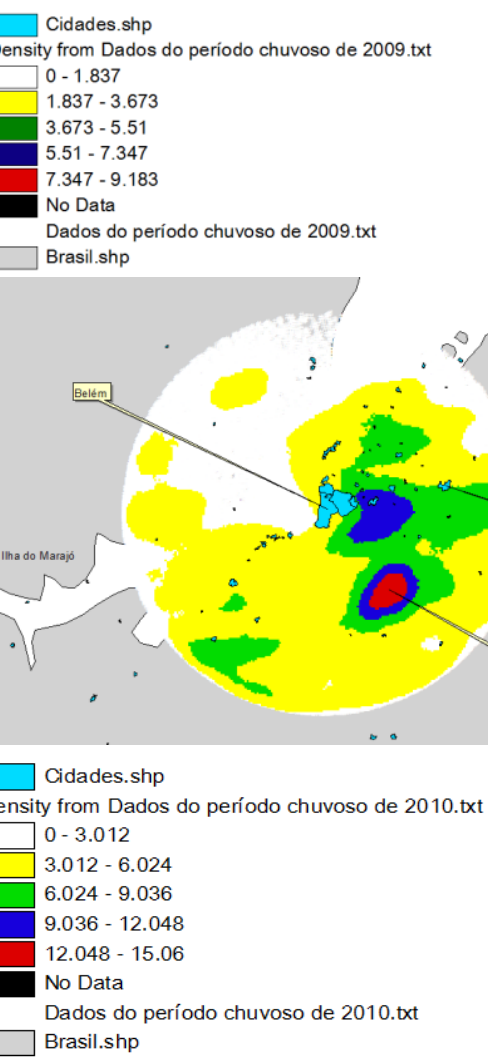

(d) (b)
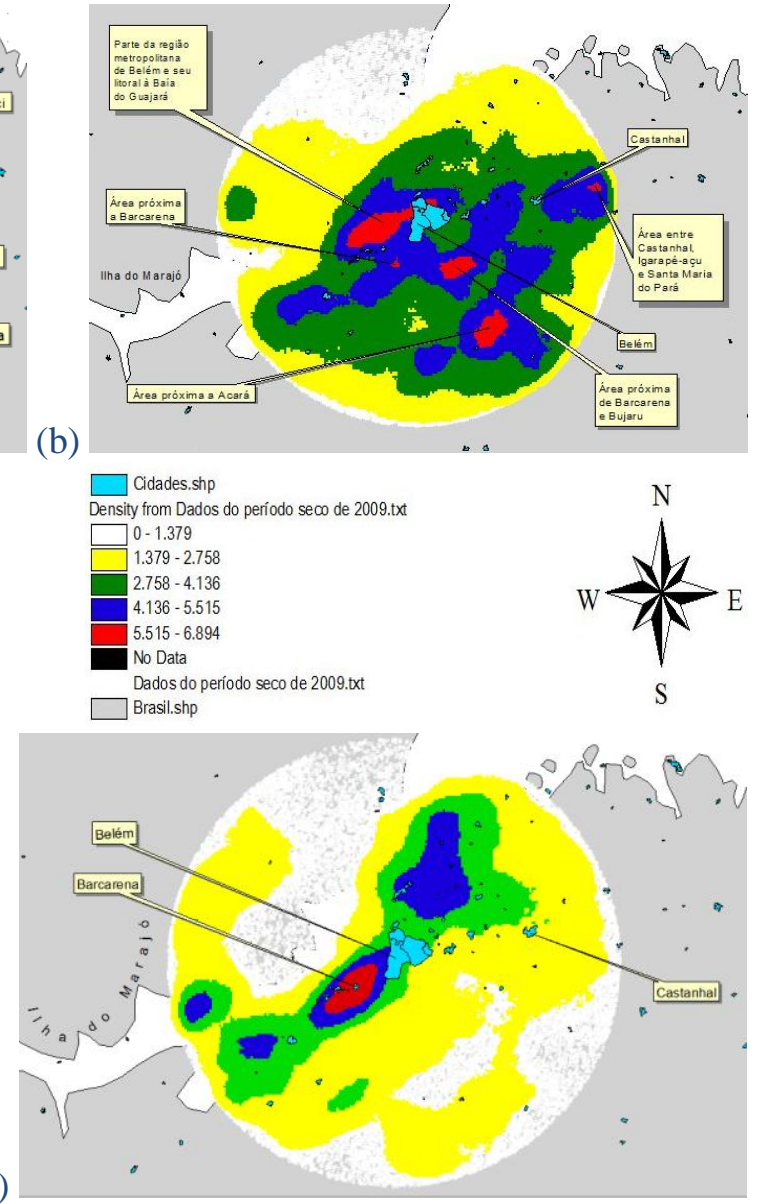

Cidades.shp

Density from Dados do período seco de 2010.txt

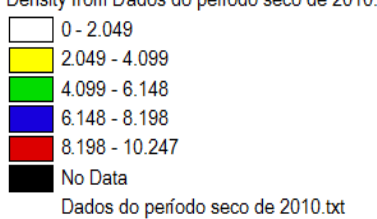

$\square$ Brasil.shp

Figura 2: Densidade espacial dos raios por $\mathrm{km}^{2}$ no ano de 2009 no período chuvoso (a) e no período seco (b); no ano de 2010 no período chuvoso (c) e no período seco (d).

Desta forma, é possível planejar os horários e as áreas para desempenhar serviços, instalações e manutenções, como em estações elétricas e em redes de telecomunicações, evitando fatalidades e prejuízos materiais, buscando desenvolver sistemas de proteção eficiente para pessoas e equipamentos nesta região e, além disso, torna-se um ensejo inacreditável vivenciar a aplicação da matemática em fenômenos do mundo real.

Palavras-chave: Distribuição Temporal, Distribuição Espacial, Descargas Atmosféricas

\section{Referências}

[1] M. F. CORREIA, W. R. G. FARIAS, Descargas atmosféricas e interrupções de energia elétrica na área da CHESF: relação com variáveis atmosféricas em anos de El Niño e La Niña, Rev. Bras. de Meteor., vol. 23, pp. 270-281, (2008). 